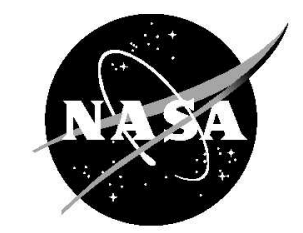

Crack-Detection Experiments on Simulated Turbine Engine Disks in NASA Glenn Research Center's Rotordynamics Laboratory

Mark R. Woike

Glenn Research Center, Cleveland, Ohio

Ali Abdul-Aziz

Cleveland State University, Cleveland, Ohio 


\section{NASA STI Program . . . in Profile}

Since its founding, NASA has been dedicated to the advancement of aeronautics and space science. The NASA Scientific and Technical Information (STI) program plays a key part in helping NASA maintain this important role.

The NASA STI Program operates under the auspices of the Agency Chief Information Officer. It collects, organizes, provides for archiving, and disseminates NASA's STI. The NASA STI program provides access to the NASA Aeronautics and Space Database and its public interface, the NASA Technical Reports Server, thus providing one of the largest collections of aeronautical and space science STI in the world. Results are published in both non-NASA channels and by NASA in the NASA STI Report Series, which includes the following report types:

- TECHNICAL PUBLICATION. Reports of completed research or a major significant phase of research that present the results of NASA programs and include extensive data or theoretical analysis. Includes compilations of significant scientific and technical data and information deemed to be of continuing reference value. NASA counterpart of peer-reviewed formal professional papers but has less stringent limitations on manuscript length and extent of graphic presentations.

- TECHNICAL MEMORANDUM. Scientific and technical findings that are preliminary or of specialized interest, e.g., quick release reports, working papers, and bibliographies that contain minimal annotation. Does not contain extensive analysis.

- CONTRACTOR REPORT. Scientific and technical findings by NASA-sponsored contractors and grantees.
- CONFERENCE PUBLICATION. Collected papers from scientific and technical conferences, symposia, seminars, or other meetings sponsored or cosponsored by NASA.

- SPECIAL PUBLICATION. Scientific, technical, or historical information from NASA programs, projects, and missions, often concerned with subjects having substantial public interest.

- TECHNICAL TRANSLATION. Englishlanguage translations of foreign scientific and technical material pertinent to NASA's mission.

Specialized services also include creating custom thesauri, building customized databases, organizing and publishing research results.

For more information about the NASA STI program, see the following:

- Access the NASA STI program home page at http://www.sti.nasa.gov

- E-mail your question via the Internet to help@ sti.nasa.gov

- Fax your question to the NASA STI Help Desk at $443-757-5803$

- Telephone the NASA STI Help Desk at 443-757-5802

- Write to: NASA Center for AeroSpace Information (CASI) 7115 Standard Drive Hanover, MD 21076-1320 


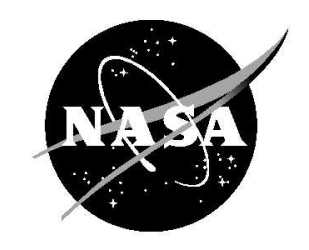

\section{Crack-Detection Experiments on Simulated Turbine Engine Disks in NASA Glenn Research Center's Rotordynamics Laboratory}

Mark R. Woike

Glenn Research Center, Cleveland, Ohio

Ali Abdul-Aziz

Cleveland State University, Cleveland, Ohio

Prepared for the

48th Aerospace Sciences Meeting

sponsored by the American Institute of Aeronautics and Astronautics

Orlando, Florida, January 4-7, 2010

National Aeronautics and

Space Administration

Glenn Research Center Cleveland, Ohio 44135 
This report contains preliminary findings, subject to revision as analysis proceeds.

Trade names and trademarks are used in this report for identification only. Their usage does not constitute an official endorsement, either expressed or implied, by the National Aeronautics and Space Administration.

Level of Review: This material has been technically reviewed by technical management.

Available from

NASA Center for Aerospace Information 7115 Standard Drive

Hanover, MD 21076-1320
National Technical Information Service 5301 Shawnee Road Alexandria, VA 22312

Available electronically at http://gltrs.grc.nasa.gov 


\title{
Crack-Detection Experiments on Simulated Turbine Engine Disks in NASA Glenn Research Center's Rotordynamics Laboratory
}

\author{
Mark R. Woike \\ National Aeronautics and Space Administration \\ Glenn Research Center \\ Cleveland, Ohio 44135 \\ Ali Abdul-Aziz \\ Cleveland State University \\ Cleveland, Ohio 44115
}

\begin{abstract}
The development of new health-monitoring techniques requires the use of theoretical and experimental tools to allow new concepts to be demonstrated and validated prior to use on more complicated and expensive engine hardware. In order to meet this need, significant upgrades were made to NASA Glenn Research Center's Rotordynamics Laboratory and a series of tests were conducted on simulated turbine engine disks as a means of demonstrating potential crack-detection techniques. The Rotordynamics Laboratory consists of a high-precision spin rig that can rotate subscale engine disks at speeds up to $12000 \mathrm{rpm}$. The crack-detection experiment involved introducing a notch on a subscale engine disk and measuring its vibration response using externally mounted blade-tip-clearance sensors as the disk was operated at speeds up to $12000 \mathrm{rpm}$. Testing was accomplished on both a clean baseline disk and a disk with an artificial crack: a 50.8-mm- (2-in.-) long introduced notch. The disk's vibration responses were compared and evaluated against theoretical models to investigate how successful the technique was in detecting cracks. This paper presents the capabilities of the Rotordynamics Laboratory, the baseline theory and experimental setup for the crack-detection experiments, and the associated results from the latest test campaign.
\end{abstract}

\section{Introduction}

The development of fault-detection techniques for the in situ health monitoring of gas turbine engines is of high interest to NASA's Aviation Safety Program (AVSP). The rotating components of modern gas turbine engines operate in severe environmental conditions and are exposed to high thermal and mechanical loads. The cumulative effects of these loads over time lead to high stresses, structural deformity, and eventual component failure. Current risk-mitigation practices involve periodic inspections and schedule-based maintenance of engine components to ensure their integrity over the lifetime of the engine. However, these methods have their limitations, and failures are experienced leading to unscheduled maintenance and unplanned engine shutdowns. To prevent these failures and enhance aviation safety, the NASA Integrated Vehicle Health Management (IVHM) Project, as part of the overall AVSP, is investigating new types of sensor technologies and methods for the in situ structural health monitoring and detection of flaws in gas turbine engines. The successful development and implementation of such technology and health-monitoring techniques requires the use of both theoretical and experimental tools to allow new concepts to be investigated and demonstrated prior to use on more complicated and expensive hardware. In order to meet this need, research has been conducted at the NASA Glenn Research Center to develop both global and local approaches for monitoring critical rotor components (Refs. 1 to 6). 
As part of these ongoing research activities, significant upgrades were made to Glenn's Rotordynamics Laboratory and a series of experiments were conducted on simulated turbine engine disks to test the applicability of potential crack-detection techniques. The Rotordynamics Laboratory consists of a high-precision spin rig that can rotate subscale engine disks at speeds up to $12000 \mathrm{rpm}$. The rig provides a low-cost venue for developing and validating lower Technology Readiness Level (TRL) detection schemes prior to implementing them on more expensive and complicated engine hardware. The spin rig was installed and used from 2003 to 2005 to conduct crack-detection experiments in rotating components (Refs. 5 and 6). However, during this period, the rig's speed was limited to a maximum of $5000 \mathrm{rpm}$. Over the past year, improvements were made to the spin rig that increased its operational speed to $12000 \mathrm{rpm}$ and enhanced its capability to support crack-detection experiments.

The crack-detection methodology that was recently investigated on the High Precision Spin Rig involved introducing a notch on a simulated turbine engine disk and monitoring its vibration response as the disk was rotated at speeds up to $12000 \mathrm{rpm}$. The vibration response was measured using externally mounted capacitive blade tip clearance sensors. Testing was performed on a clean undamaged baseline disk and a disk with a 50.8-mm- (2-in.-) long notch machined into the disk to simulate a crack. The vibration responses were compared and evaluated against the theoretical models to investigate the applicability and success of detecting the notch. This paper presents an overview of this ongoing research activity, including the capability of the High Precision Spin Rig, the baseline theory behind the crackdetection experiment, and the experimental results from the latest test campaign.

\section{High Precision Spin Rig Description}

Figure 1 shows the Rotordynamics Laboratory's High Precision Spin Rig, which can accommodate simulated engine rotor disks of up to $235 \mathrm{~mm}(9.25 \mathrm{in}$.) in diameter. It has a stainless steel shaft with a length of $781 \mathrm{~mm}(30.75 \mathrm{in}$.) and diameter of $20 \mathrm{~mm}(0.79 \mathrm{in}$.). The shaft is supported by precision contact ball bearings on each end and has adjustable dampers that were positioned along the length of the shaft for these experiments. An encoder mounted on the end of the shaft was used by the control system to provide closed-loop control of rig speed. A secondary optical tachometer was used to record the speed into the data system and to synchronize the data to the rig's rotation. A 12-hp custom-built, brushless direct-current $(\mathrm{dc})$ motor was used to rotate the spin rig and the simulated engine disks. This motor was installed during the last year and replaced the 1-hp motor that was previously used on the rig. The new motor increased the rig's operational speed from 5000 to $12000 \mathrm{rpm}$ and allowed testing to be accomplished at higher speeds than had been achieved previously.

The rig was set up to acquire two channels of radial blade-tip-clearance data from the simulated engine disk using capacitive displacement sensors. Theses sensors were developed as part of a NASA Small Business Innovation Research (SBIR) contract and were different from traditional capacitive sensors in that their operation was based on a dc offset technique instead of the typical modulation technique (Ref. 6). A National Instruments System was used to acquire data from the capacitive displacement probes at a fixed sampling rate of $1 \mathrm{MHz}$. This system and its application software were delivered as part of the SBIR contract for the capacitive blade-tip-clearance sensors. The system used custom data acquisition and processing applications that were tailored for acquiring and processing data from the capacitive sensors. As part of ongoing spin rig improvement activities, the National Instruments System was upgraded to the most current version of hardware and software, which resulted in increased data acquisition and processing capability. In addition, the existing analog channel capacity was expanded from 4 to 20 channels, allowing for future incorporation of additional sensors. Efforts are underway to further modernize and improve the data acquisition system with new software features and additional types of sensors. 


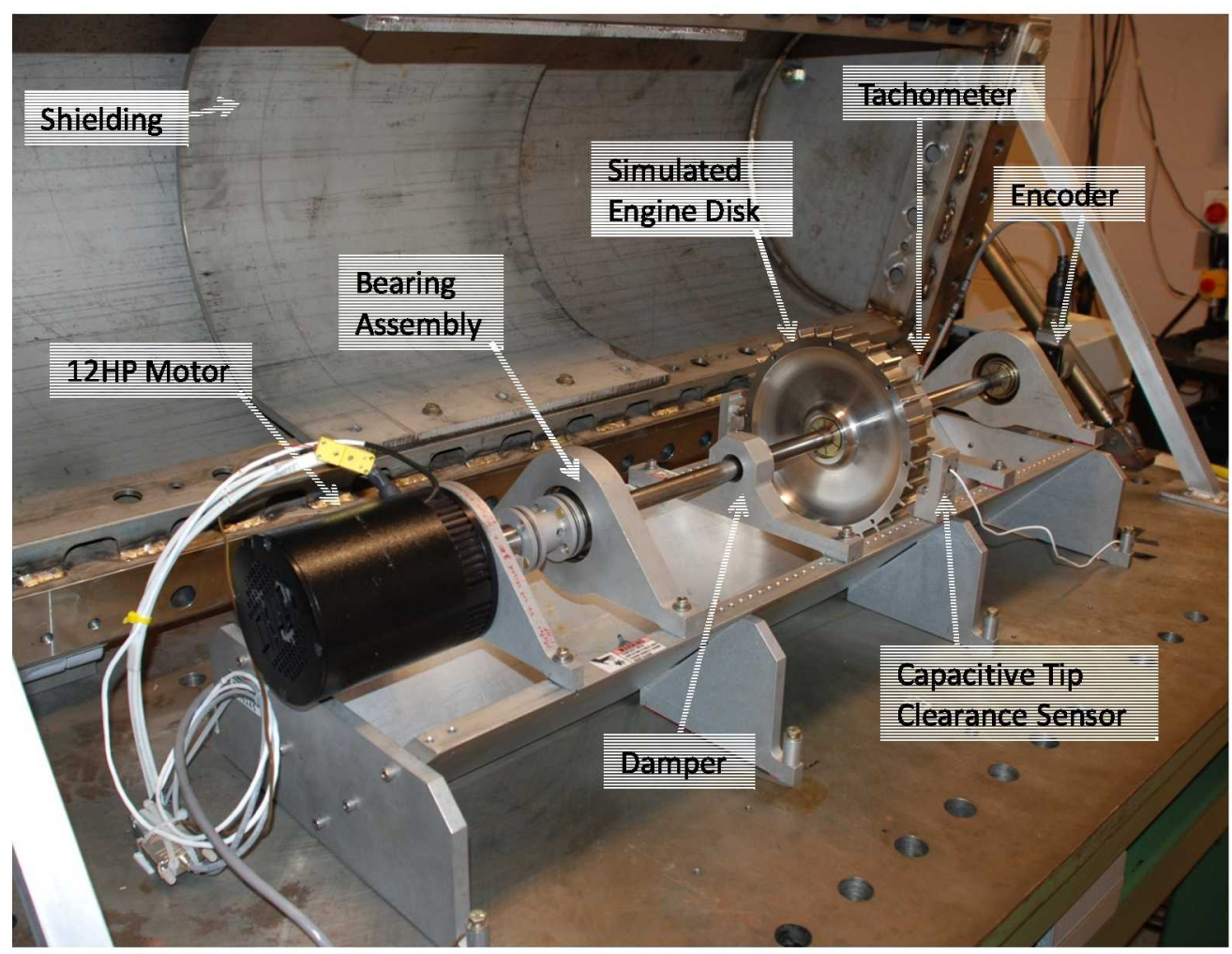

Figure 1.-High Precision Spin Rig.

\section{Experimental Theory and Setup}

The theory behind the crack-detection methodology that was investigated was based on previous theoretical and experimental work performed by Gyekenyesi et al., (Refs. 5 and 6) Haase and Drumm, (Ref. 7) and Abdul-Aziz et al. (Refs. 1 and 2). The goal of this experiment was to determine if the crackdetection methodology investigated in these earlier studies could be validated by using the upgraded spin rig to conduct tests on simulated engine rotor disks with an introduced notch. This paper summarizes the theory behind the detection technique. Additional details describing the technique and its associated modeling are available in References 5 to 7.

The detection methodology is based on monitoring the vibration response of rotating disks to determine if a crack has developed. The theory implies that a defect, such as a crack, creates minute deformations in the disk as it is rotated. The deformation, in turn, creates a speed-dependent shift in the disk's center of mass. It was theorized that this shift could be detected by analyzing the amplitude and phase of the vibration response of the combined disk-rotor system (Refs. 5 and 6). The system's behavior was modeled after a 2-degree-of-freedom Jeffcott rotor. The model predicts that the vibration amplitude peaks when a clean, undamaged disk goes through the first critical speed, but heads to a lower steadystate value as the speed is increased above the critical speed. Correspondingly, the phase shifts $180^{\circ}$ when going through the first critical speed and then stabilizes to a steady-state value as the speed is increased past critical. At this point, the rotor is rotating about the combined system's center of mass and has stabilized. However, as the speed of a cracked disk is increased, centrifugal forces open the crack. This, in turn, deforms the disk and shifts its center of mass. At speeds above critical, the crack-induced shift in the disk's center of mass starts to grow and dominate the overall system's vibration response. The modeling predicts that, instead of heading toward a steady-state value, the vibration amplitude will change as a second-order function of rotational speed as it is increased beyond the first critical speed (Ref. 7). This can be detected by analyzing the vibration response of the disk-rotor system, particularly the amplitude and phase of the first harmonic, as the system is operated over a range of speeds. 
The testing approach used in this experiment was to spin a simulated engine disk over a speed range from 0 to $12000 \mathrm{rpm}$ and simultaneously record its vibration response. The vibration response was acquired using capacitive displacement probes (Fig. 2) to acquire blade-tip-clearance data. Two subscale simulated engine turbine disks were tested. The first disk was undamaged and was used to acquire the baseline vibration response data. Figure 1 shows this disk mounted on the High Precision Spin Rig. The disk had an outside diameter of $235 \mathrm{~mm}$ (9.25 in.), a bore thickness of $25.4 \mathrm{~mm}(1 \mathrm{in}$.), and an outside rim thickness of $31.75 \mathrm{~mm}$ (1.25 in.). The thinnest portion of the disk's web was $2.54 \mathrm{~mm}(0.10 \mathrm{in}$.). Thirtytwo blades were spaced evenly around the circumference of the disk. Each blade had a cross section of $31.75 \mathrm{~mm}(1.25 \mathrm{in}$.) by $3.30 \mathrm{~mm}(0.13 \mathrm{in}$.) and a height of $8.38 \mathrm{~mm}(0.33 \mathrm{in}$.). References 1 and 2 give additional details on the geometry of the disk. Two materials were considered for the manufacturing of the disk: nickel-base alloy Haynes X-750 (Haynes International, Inc.) and Grade 2 titanium. Simulated gas turbine engine disks were made of each material, and their physical properties (Ref. 8) are listed in Table I. For this experiment, testing was only conducted on the Haynes X-750 disks, which each had a mass of $4.88 \mathrm{~kg}(10.75 \mathrm{lb})$.

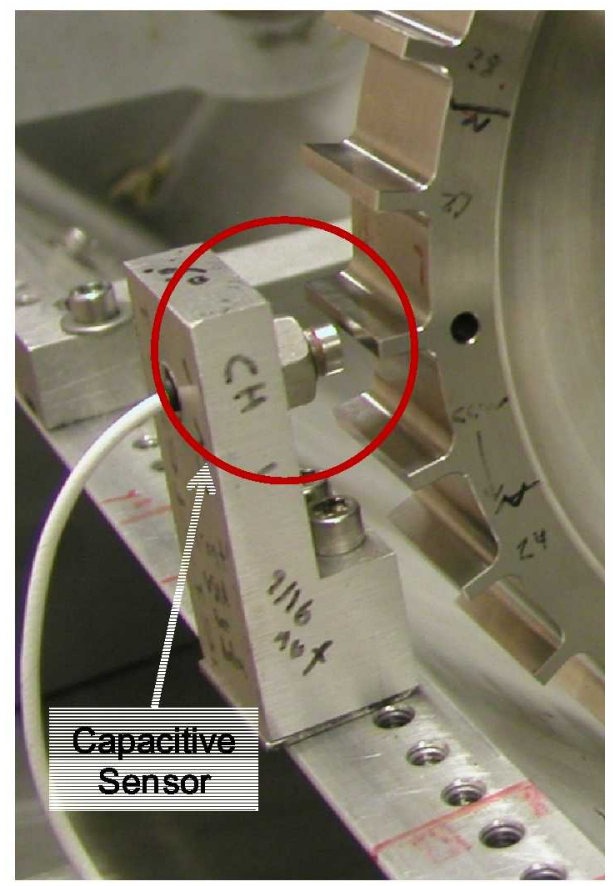

Figure 2.-Capacitive displacement sensor.

TABLE I.-PHYSICAL PROPERTIES OF HAYNES X-750 AND TITANIUM GRADE 2

\begin{tabular}{|l|c|c|}
\hline \multicolumn{1}{|c|}{ Material } & $\begin{array}{c}\text { Haynes } \\
\text { X-750 }\end{array}$ & $\begin{array}{c}\text { Titanium } \\
\text { Grade 2 }\end{array}$ \\
\hline Elastic modulus, GPa & 214 & 105 \\
Poisson's ratio & 0.31 & 0.34 \\
Mass density, g/cm ${ }^{3}$ & 8.26 & 4.50 \\
Tensile strength, MPa & 1325 & 345 \\
Yield strength, $\mathrm{MPa}$ & 975 & 276 \\
Thermal expansion coefficient, $\mathrm{cm} /{ }^{\circ} \mathrm{C}$ & $14.3 \times 10^{-6}$ & $10.1 \times 10^{-6}$ \\
\hline
\end{tabular}




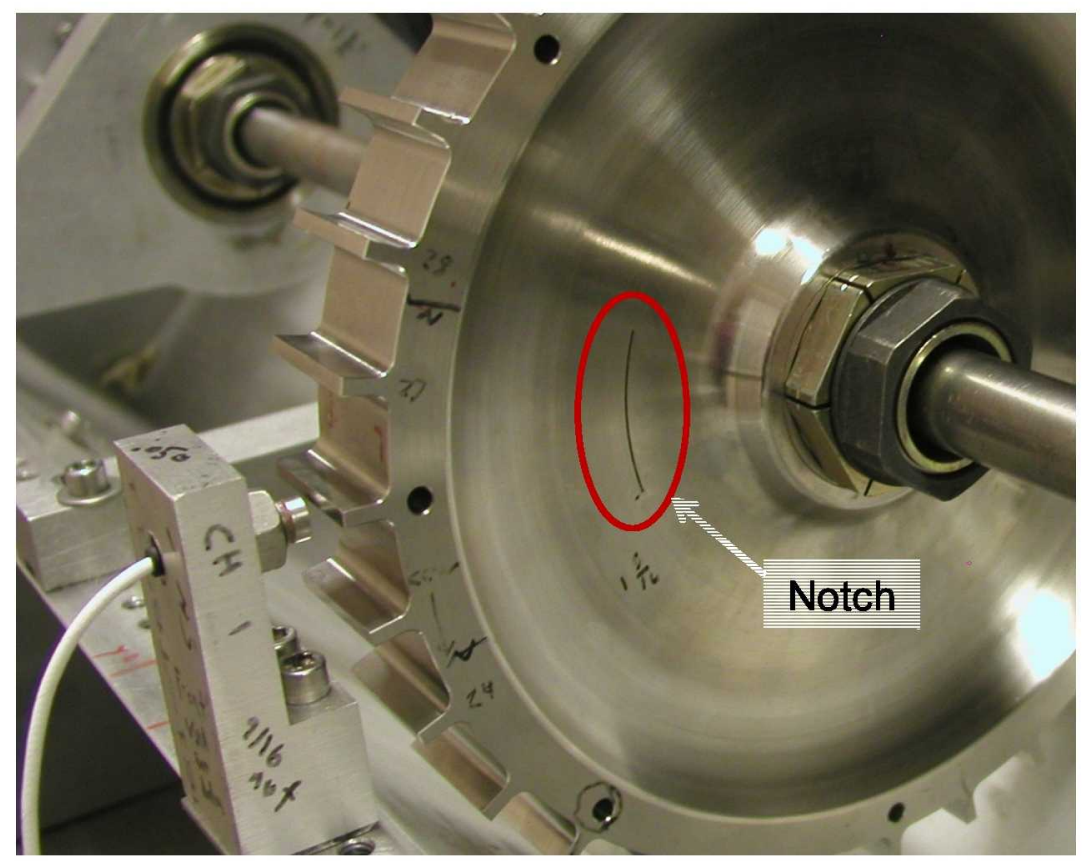

Figure 3.-Simulated engine disk with notch.

The second disk is shown in Figure 3. It was identical to the baseline disk with the exception that a 50.8-mm-(2-in.-) long notch had been introduced in its midspan region to imitate a crack in the disk. The midspan region was selected because prior finite-element analysis had shown that this area experienced high stress levels during operation. The data acquired from this disk were compared with the data from the undamaged baseline disk to determine if the simulated crack could be detected by analyzing the vibration response. Supportive analytical calculations were made using finite-element analysis (Refs. 1 and 2) to complement the experimental work and determine the disk's material limitations.

Figures 4 and 5 show the results from the finite-element analysis. Radial stress variation as a function of rotational speed for the disk with the 50.8-mm-long notch is shown in Figure 4. The analysis was carried out for both the Haynes X-750 and titanium disks. In addition to the expected stresses, Figure 4 shows the yield curve for both materials. The analysis showed that the titanium disk would reach the yield level at $\sim 8000 \mathrm{rpm}$ and that the Haynes $\mathrm{X}-750$ disk would reach the yield level at $\sim 12000 \mathrm{rpm}$. This analysis provided guidelines on the maximum speed that the disk could be operated at without exceeding the material's yield limit and causing a premature rupture of the disk during operation. For the Haynes $\mathrm{X}-750$ disk, which was tested subsequently, the researchers decided that it would be acceptable to operate at speeds up to $12000 \mathrm{rpm}$ because this was just on the edge of the yield limit.

Figure 5 shows the radial-tip-displacement profile for the disk with the 50.8-mm (2-in.) notch. As in the previous case, Haynes $\mathrm{X}-750$ and titanium disks were analyzed. For the Haynes $\mathrm{X}-750$ disk, a growth of $\sim 0.06 \mathrm{~mm}(\sim 0.002 \mathrm{in}$.) was expected at the highest operating speed, $12000 \mathrm{rpm}$. Although this was within the detection limit of the blade-tip-clearance instrumentation, it should be noted that the major effect that was to be monitored in the experiment was that of the notch on the combined center of mass of the disk rotor system - not just the radial tip growth of the disk.

For the experimentation phase, a series of test runs were conducted on both the baseline and notched disks to determine if the notch could be detected using the methodology described in this section. Bladetip-clearance data were acquired as the disk was operated through various speed profiles as a means of recording the disk's vibration response. The first harmonic component of the tip-clearance data was then analyzed to determine if the amplitude and phase exhibited the expected characteristics associated with the simulated crack in the disk. 


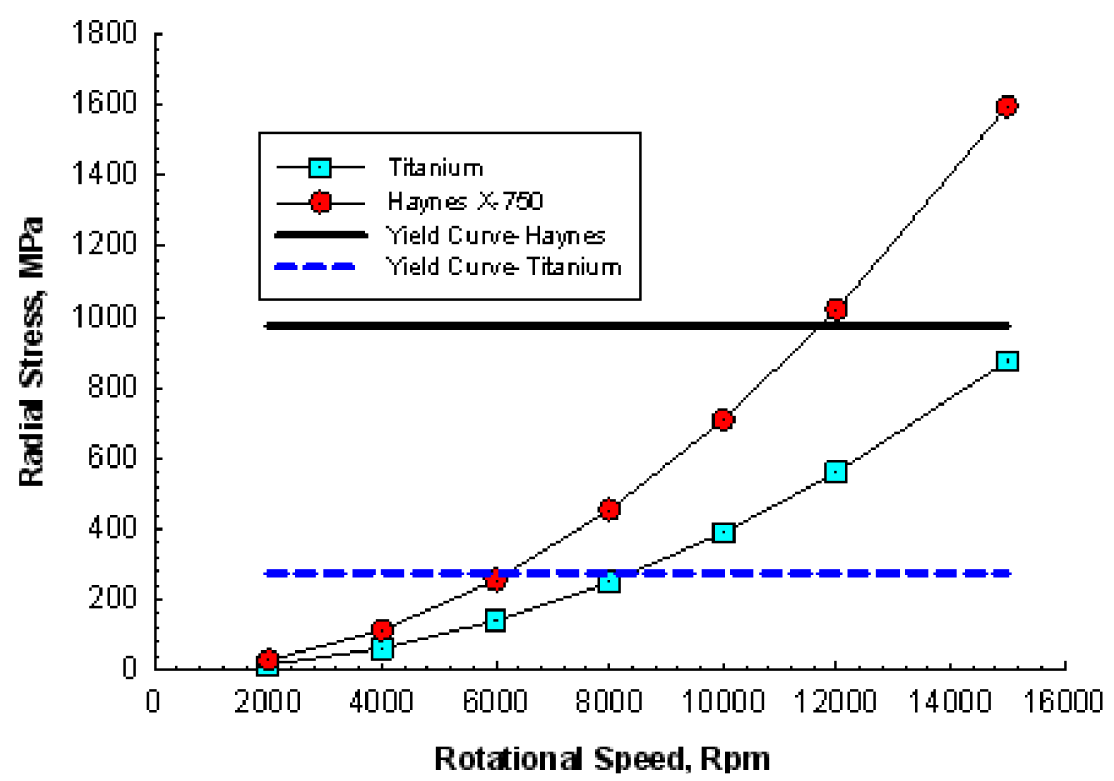

Figure 4.-Radial stress as a function of speed for the notched disk.

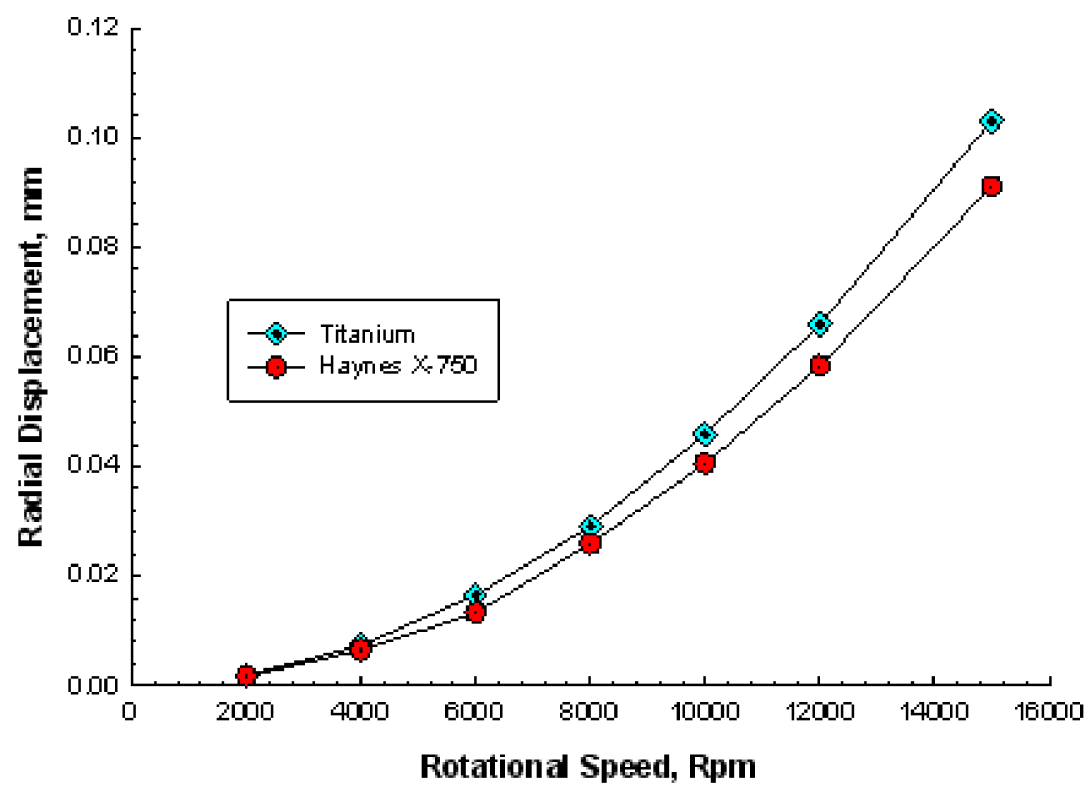

Figure 5.-Radial displacement as a function of speed for the notched disk. 


\section{Experimental Results}

The experimentation consisted of operating the baseline and notched disks at several speed profiles and recording their vibration responses using the capacitive blade-tip-clearance sensors. Approximately 15 test runs were conducted for each disk. Figure 6 shows a typical test run, or cycle. This consisted of ramping up the disk's speed from $0 \mathrm{rpm}$ to a predefined maximum speed, remaining on condition for 30 to $60 \mathrm{~s}$, then ramping back down to $0 \mathrm{rpm}$. Blade-tip-clearance data were acquired over the entire cycle. Data sets were acquired at ramp rates of 60 and $100 \mathrm{rpm} / \mathrm{s}$ for peak operating speeds of 5000,10000 , and $12000 \mathrm{rpm}$. In addition to the typical test profile shown in Figure 6, more complex mission profiles were conducted where the speed was ramped to various power levels in an attempt to simulate the rigorous loading conditions that an engine would experience during a typical mission profile. For diagnostic purposes, data sets also were acquired at several steady-state speed conditions. Only a subset of the test runs is covered in this paper because these runs, which are shown in Table II, are thought to be representative of the entire test series.

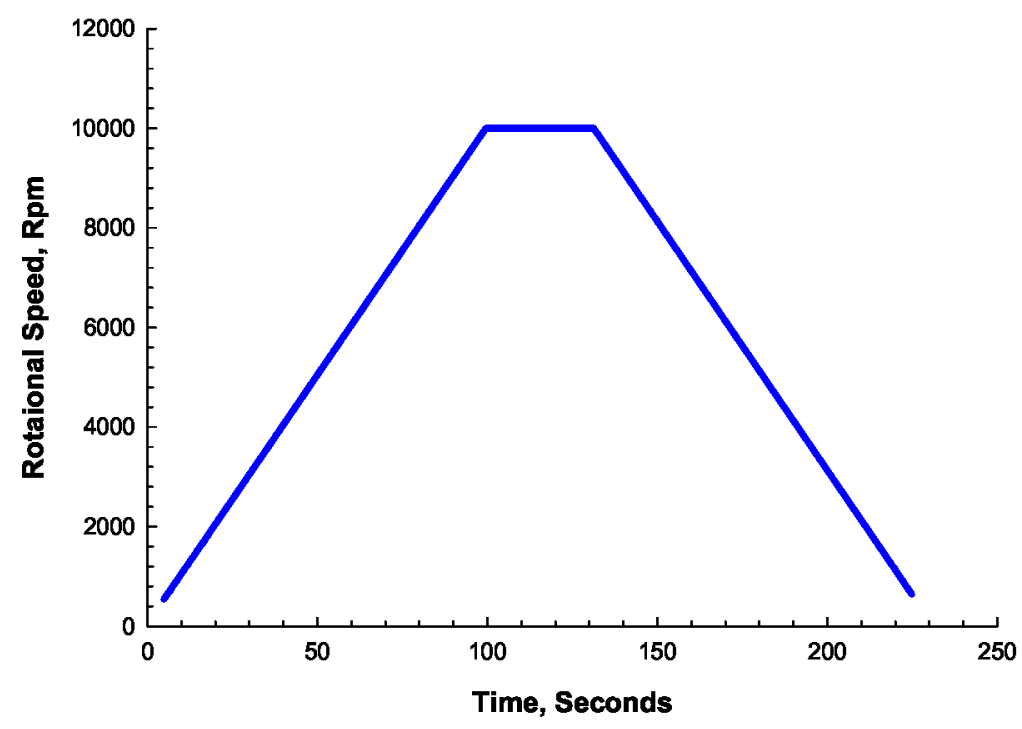

Figure 6.-Typical test-cycle profile.

TABLE II.-TEST RUNS FOR THE BASELINE AND NOTCHED DISKS THAT ARE DISCUSSED IN THE FOLLOWING SECTIONS

\begin{tabular}{|c|l|}
\hline Case & \multicolumn{1}{|c|}{ Test } \\
\hline 1 & $5000-\mathrm{rpm}$ cycle at $100 \mathrm{rpm} / \mathrm{s}$ \\
2 & $10000-\mathrm{rpm}$ cycle at $100 \mathrm{rpm} / \mathrm{s}$ \\
3 & $12000-\mathrm{rpm}$ cycle at $100 \mathrm{rpm} / \mathrm{s}$ \\
4 & $10000-\mathrm{rpm}$ multiple-cycle run at $100 \mathrm{rpm} / \mathrm{s}$ \\
\hline
\end{tabular}




\section{A. Data Interpretation and Analysis}

The data sets were analyzed and processed using an in-house LabVIEW (National Instruments)-based software application that was previously developed as part of an SBIR contract. The analysis software was specifically tailored to acquire and postprocess blade-tip-displacement data. Figure 7 shows the data plots that were developed for each test case. As discussed earlier, the shifts in the center of mass of the disk-rotor system were tracked by analyzing the synchronous component, or first harmonic, of the vibration response recorded by the blade-tip-clearance sensors. The amplitude Bode plot displays the amplitude of the first harmonic component of the vibration in inches as a function of disk speed in thousands of revolutions per minute. The phase Bode plot displays the phase of the first harmonic component of the vibration in degrees as a function of disk speed in thousands of revolutions per minute. The vibration vector plot displays the vibration response in an $x-y$ (inches vs. inches) format. These plots were developed for all of the test cases and are the primary analysis method that was used to determine if the simulated crack could be detected in the vibration response of the system.

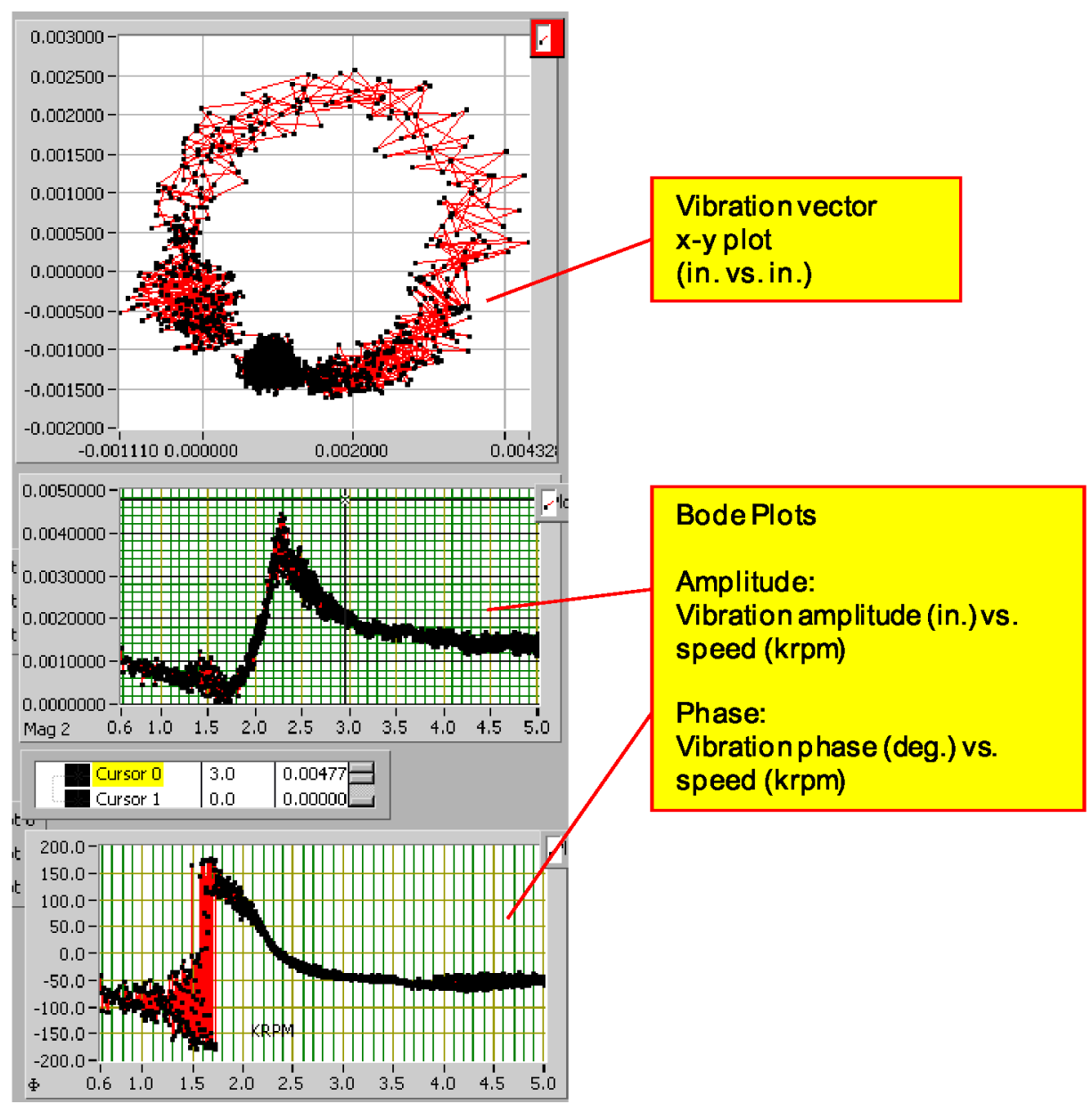

Figure 7.-Data plot description. 


\section{B. Case 1-5000-rpm Cycle at $100 \mathrm{rpm} / \mathrm{s}$}

Figure 8 shows the results from the 5000-rpm cycle for both the baseline and notched disks. In this test case, the speed of the disk was increased from 0 to $5000 \mathrm{rpm}$ at a ramp rate of $100 \mathrm{rpm} / \mathrm{s}$, held on condition for $60 \mathrm{~s}$, then ramped down to $0 \mathrm{rpm}$. The figure shows the analysis for the ramp up to $5000 \mathrm{rpm}$. Both disks exhibited the expected peak in amplitude and $180^{\circ}$ phase shift when going through the first critical speed, theoretically calculated at $\sim 2600 \mathrm{rpm}$. In each case, the peak amplitude reached was $\sim 0.10 \mathrm{~mm}(\sim 0.004 \mathrm{in}$.). For this case, no major differences were observed in the amplitude plots as the speed was increased. In addition, no major difference was noticed in the phase and $x-y$ plots. The results for this test case indicate that the loading caused by the rotational speed on the notch was negligible and that changes in the center of mass were minimal and below the detection limits. This was similar to what was previously observed in the experimental work described in Reference 6, which led to increasing the test rig's speed capability by upgrading to a higher horse power motor.

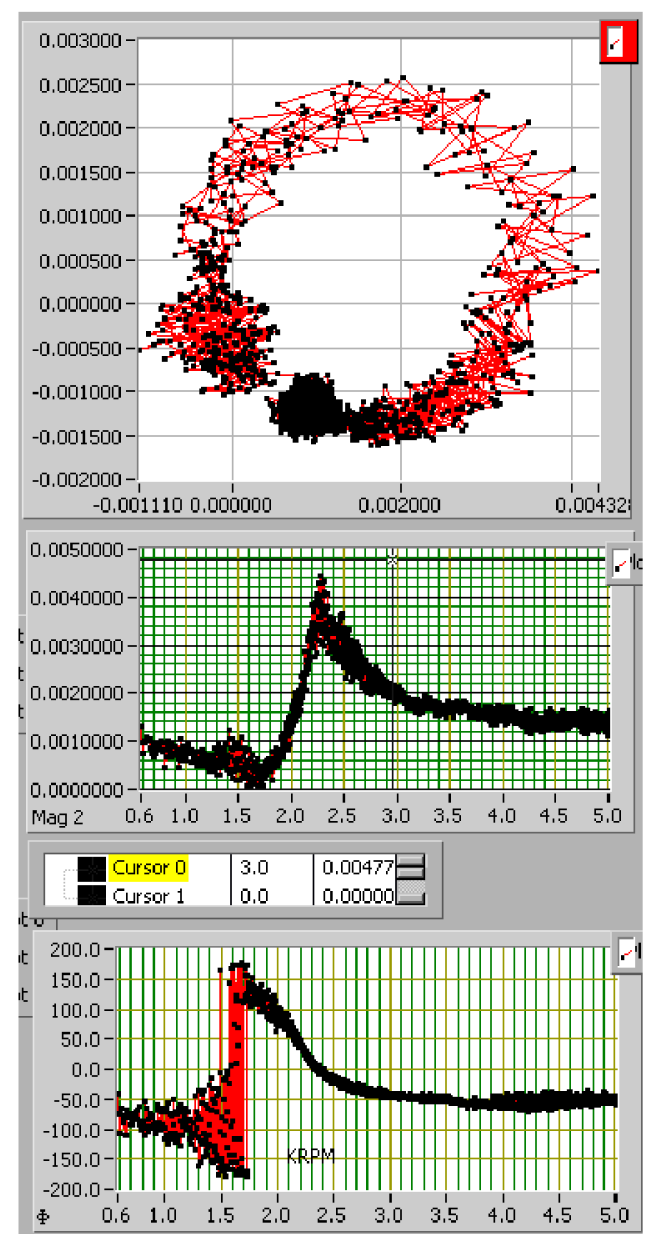

(a)

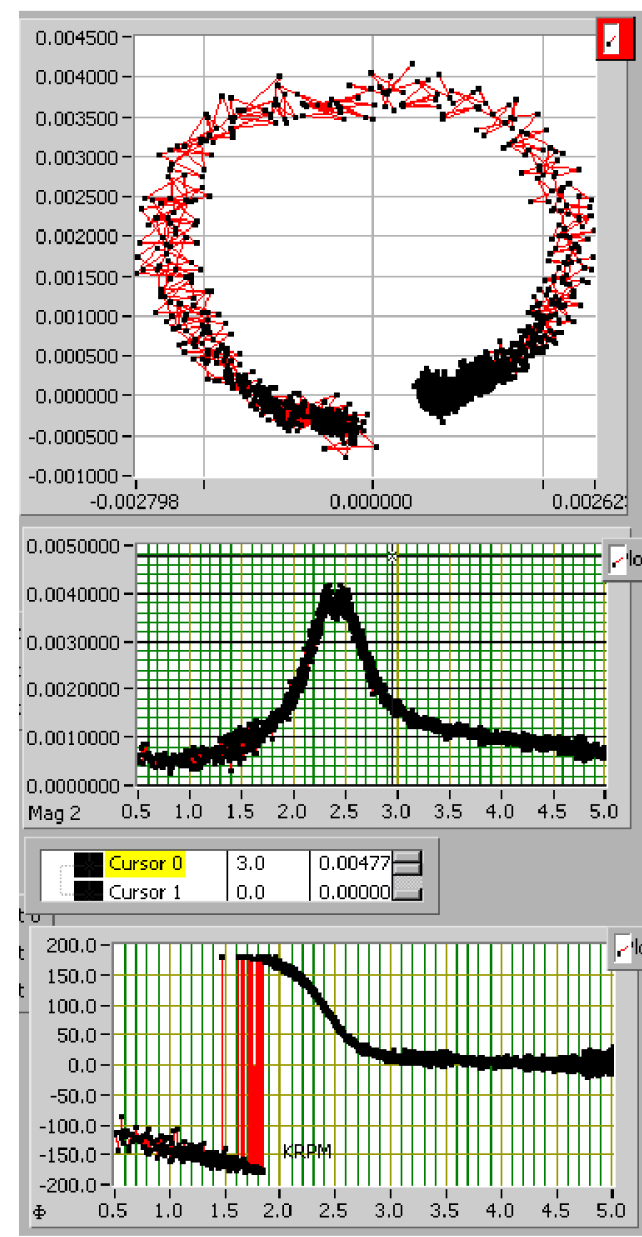

(b)

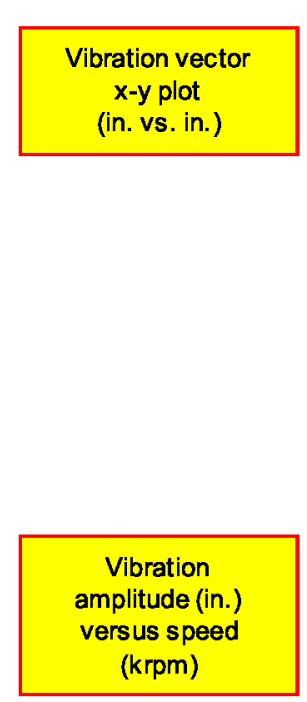

Figure 8.-5000-rpm cycle comparison. (a) Baseline disk. (b) Notched disk. 


\section{Case 2-10 000-rpm Cycle at $100 \mathrm{rpm} / \mathrm{s}$}

Figure 9 shows results from the 10000 -rpm cycle for both the baseline and notched disks. In this test case, the speed of the disk was increased from 0 to $10000 \mathrm{rpm}$ at a ramp rate of $100 \mathrm{rpm} / \mathrm{s}$, held on condition for $60 \mathrm{~s}$, then ramped down to $0 \mathrm{rpm}$. As with the previous case, the figure shows the analysis for the ramp up to $10000 \mathrm{rpm}$. Both disks exhibited the expected peak in amplitude and $180^{\circ}$ phase shift as heading through the first critical speed. As in the previous case, the peak amplitude for both disks was $\sim 0.10 \mathrm{~mm}(\sim 0.004 \mathrm{in}$.). However, in this case, a slight difference was observed in the amplitude plot for the notched disk as the speed was increased. Instead of decaying toward a steady-state value, the amplitude exhibited oscillations as the speed was increased past $5000 \mathrm{rpm}$. This may have been due to the presence of the notch. The authors believed that, for this test run, the system may have been on the verge of detecting the preexisting flaw in the disk. However, it cannot be concluded that this was definitively due to the simulated crack. It may have been due to differences in the mechanical setup of the disks. Nonetheless, a difference was noted in the amplitude plots and provided the basis for further investigation.

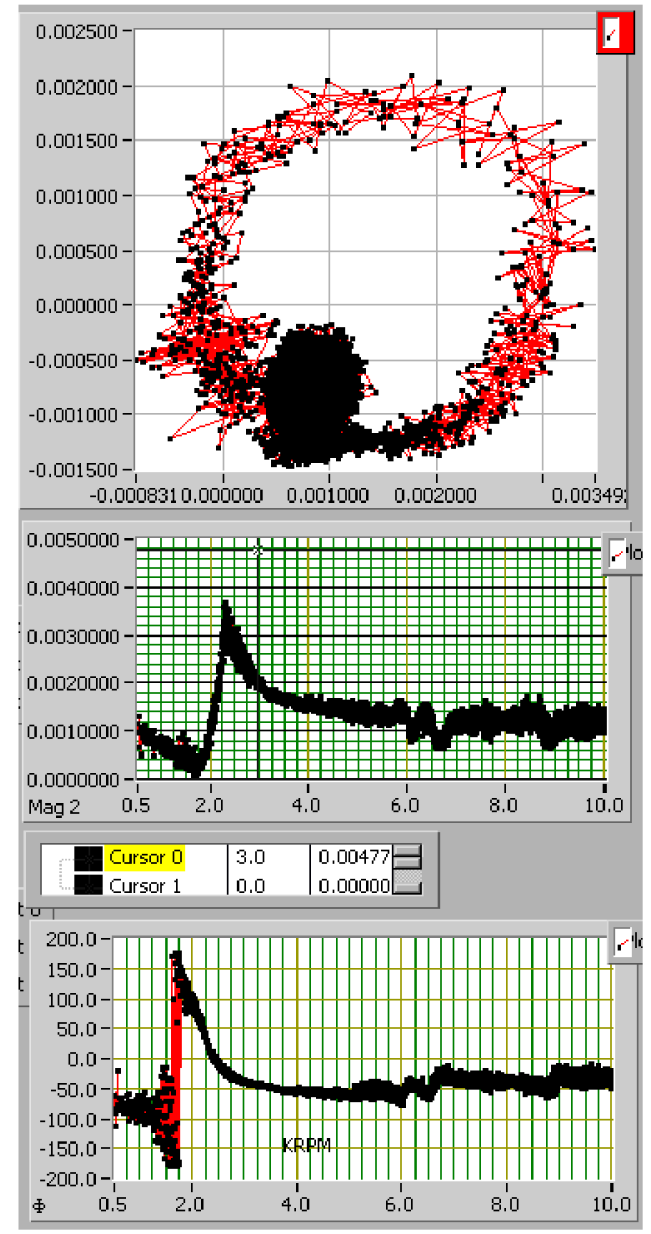

(a)

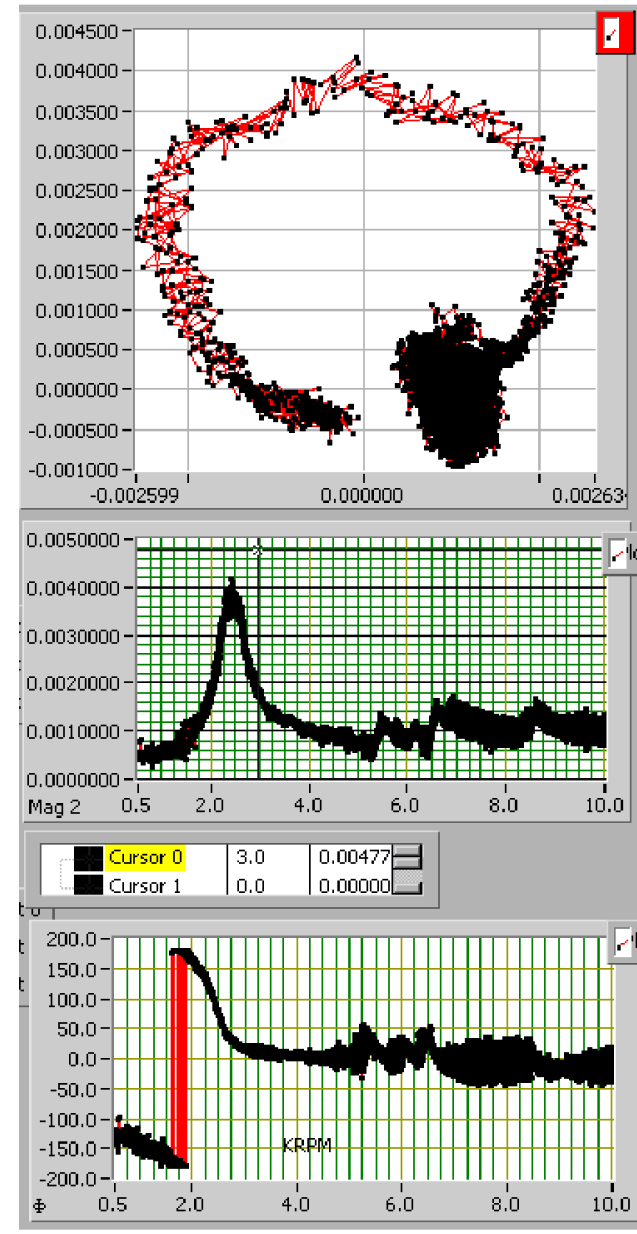

(b)

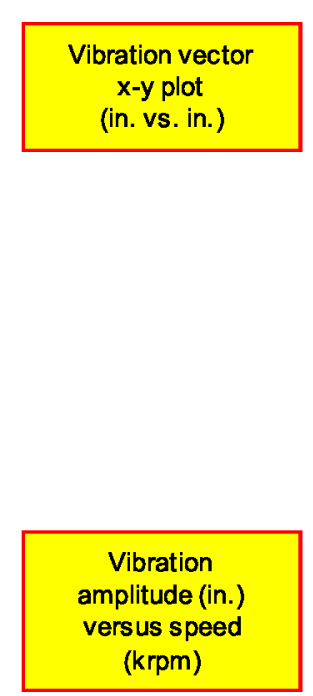

Figure 9.-10 000-rpm-cycle comparison. (a) Baseline disk. (b) Notched disk. 


\section{Case 3-12 000-rpm Cycle at $100 \mathrm{rpm} / \mathrm{s}$}

Figure 10 shows the results from the 12000 -rpm cycle for both the baseline and notched disks. In this test case, the speed of the disk was increased from 0 to $12000 \mathrm{rpm}$ at a ramp rate of $100 \mathrm{rpm} / \mathrm{s}$, held on condition for $60 \mathrm{~s}$, then ramped down to $0 \mathrm{rpm}$. The figure shows the analysis for the initial ramp up to $12000 \mathrm{rpm}$. As noted in the prior test cases, both disks exhibited a peak in the amplitude and a $180^{\circ}$ phase shift when going through the first critical speed. The amplitude for the notched disk did not show a speed-dependent variation over the speed range nor did it appear to have the fluctuations observed in the 10000 -rpm test case. However, a higher amplitude peak was experienced for the notched disk. The notched disk had an amplitude peak of $-0.15 \mathrm{~mm}(\sim 0.006 \mathrm{in}$.) in comparison to a peak amplitude of $\sim 0.10 \mathrm{~mm}(\sim 0.004 \mathrm{in}$.) for the baseline disk. In addition, there was a noticeable difference in the $\mathrm{x}-\mathrm{y}$ vibration vector plot for the notched disk. The vibration vector for the notched disk did not exhibit a circular orbit as was the case for the baseline disk, but rather it wrapped around as it moved through the speed range. In earlier studies this phenomenon was noted as an indication of the existence of a crack. ${ }^{7}$ In summary, there were noticeable differences in the vibration amplitude and $x-y$ plots, but again they do not fully follow the trend predicted by the prescribed model when a crack is present. As in the previous test case, the findings act as if there is a crack in the disk, but they are not conclusive. Again, the authors theorized that the system was on the verge of being able to detect the simulated crack.

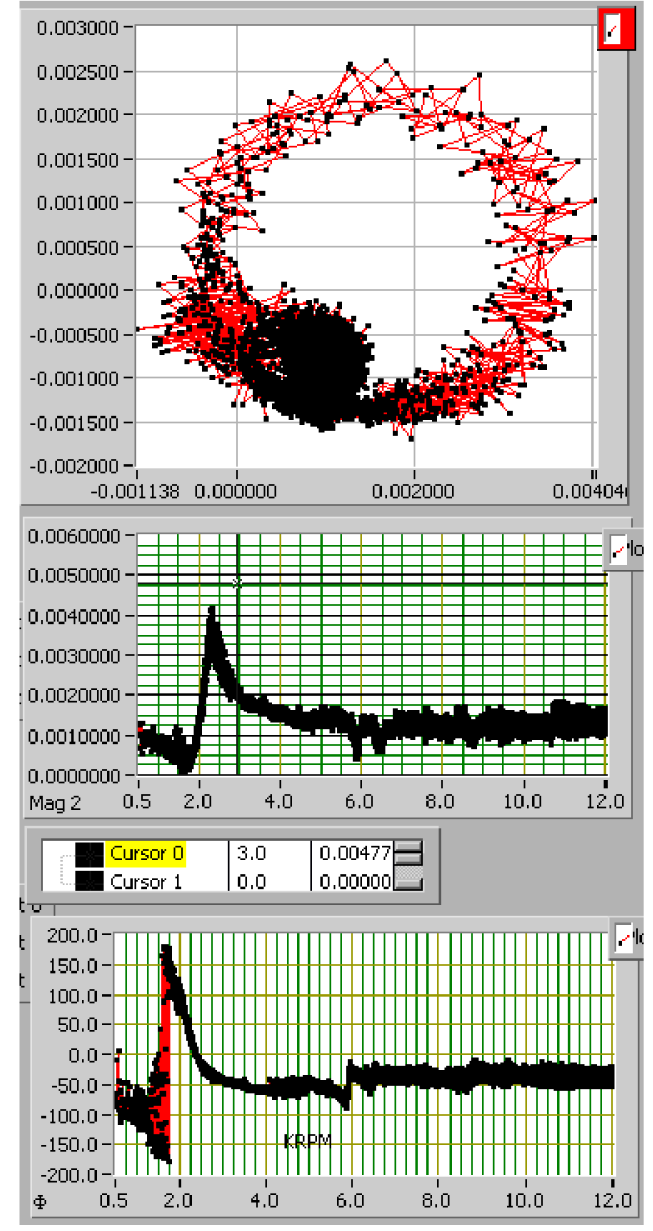

(a)

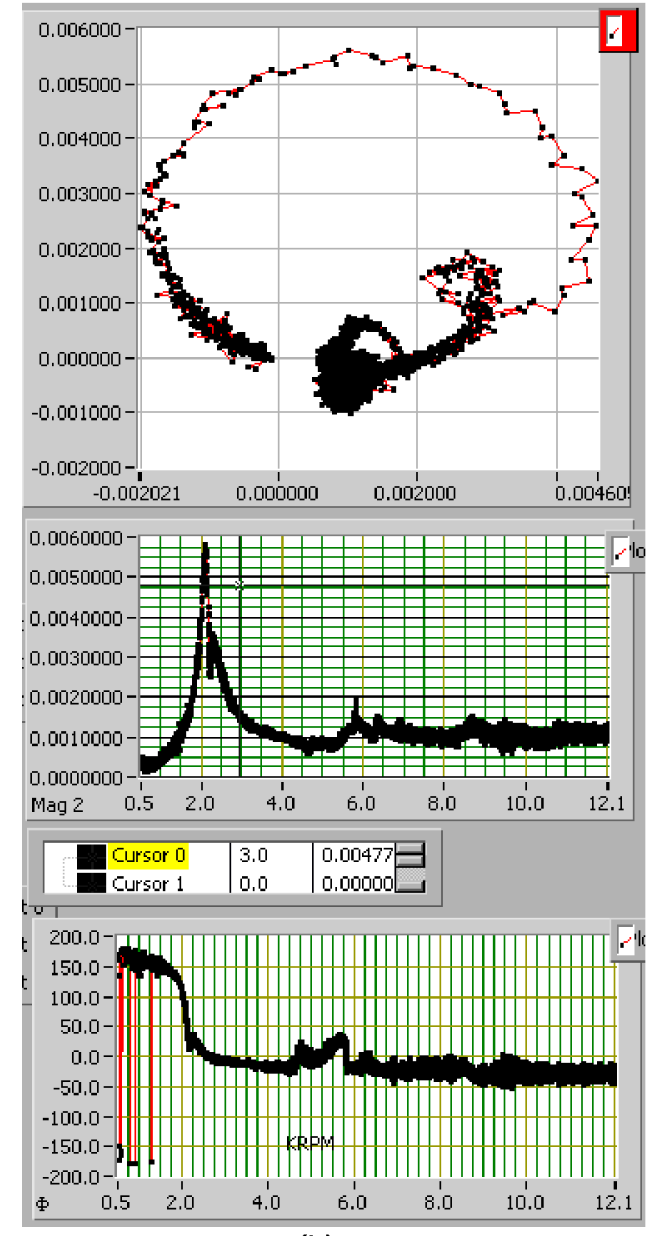

(b)

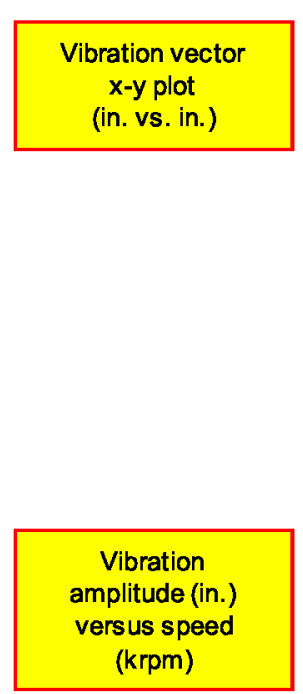

Vibration Phase (degree) versus Speed (krpm)

Figure 10.-12 000-rpm-cycle comparison. (a) Baseline disk. (b) Notched disk. 


\section{E. Case 4-10 000-rpm Multiple-Cycle Run at 100 rpm/s}

Figure 11 shows the results from the multiple-cycle run for both the baseline and notched disks. In this test case, the speed of the disk was increased from 0 to $10000 \mathrm{rpm}$ at a ramp rate of $100 \mathrm{rpm} / \mathrm{s}$, cycled between 10000 and $5000 \mathrm{rpm}$ for three cycles, then ramped down from 10000 to $0 \mathrm{rpm}$. This was done to simulate a mission profile from cruise to full power and to observe the effects of cyclical loading on the disks. The figure shows the analysis for the last cycle, starting at $10000 \mathrm{rpm}$ and ending at $0 \mathrm{rpm}$.

This test case offered promising results, with the vibration amplitude for the notched disk exhibiting the expected speed-dependent change in amplitude. As explained in Section III, the presence of a crack indicates if a second-order speed-dependent variation was observed in the vibration amplitude as it was operated in the postcritical speed regime. In this test case, a speed-dependent rise was observed in the amplitude data for the notched disk. Figure 12 shows the vibration amplitude plot for the notched disk. The area of interest showing the speed-dependent rise is highlighted within the circle. A curve-fit analysis was conducted on the vibration data in this region, and it closely followed a second-order polynomial fit. The results of this analysis are shown in Figure 13.

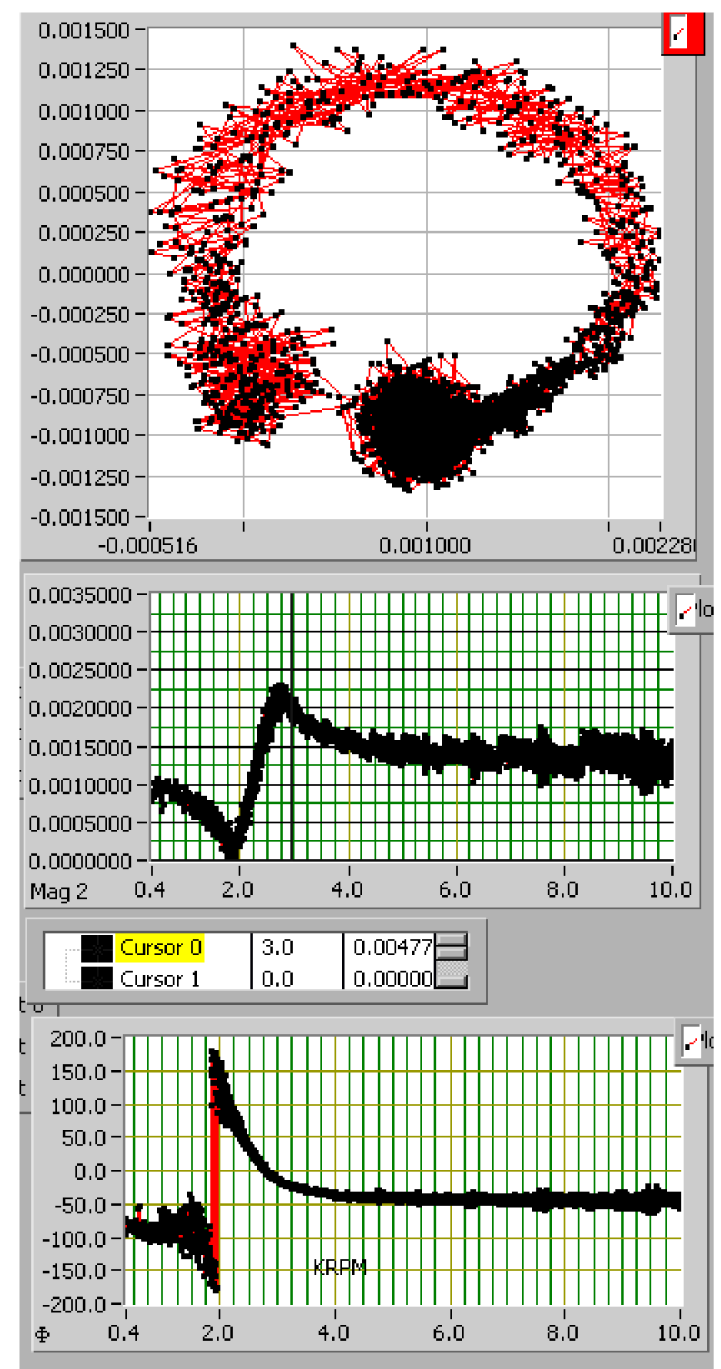

(a)

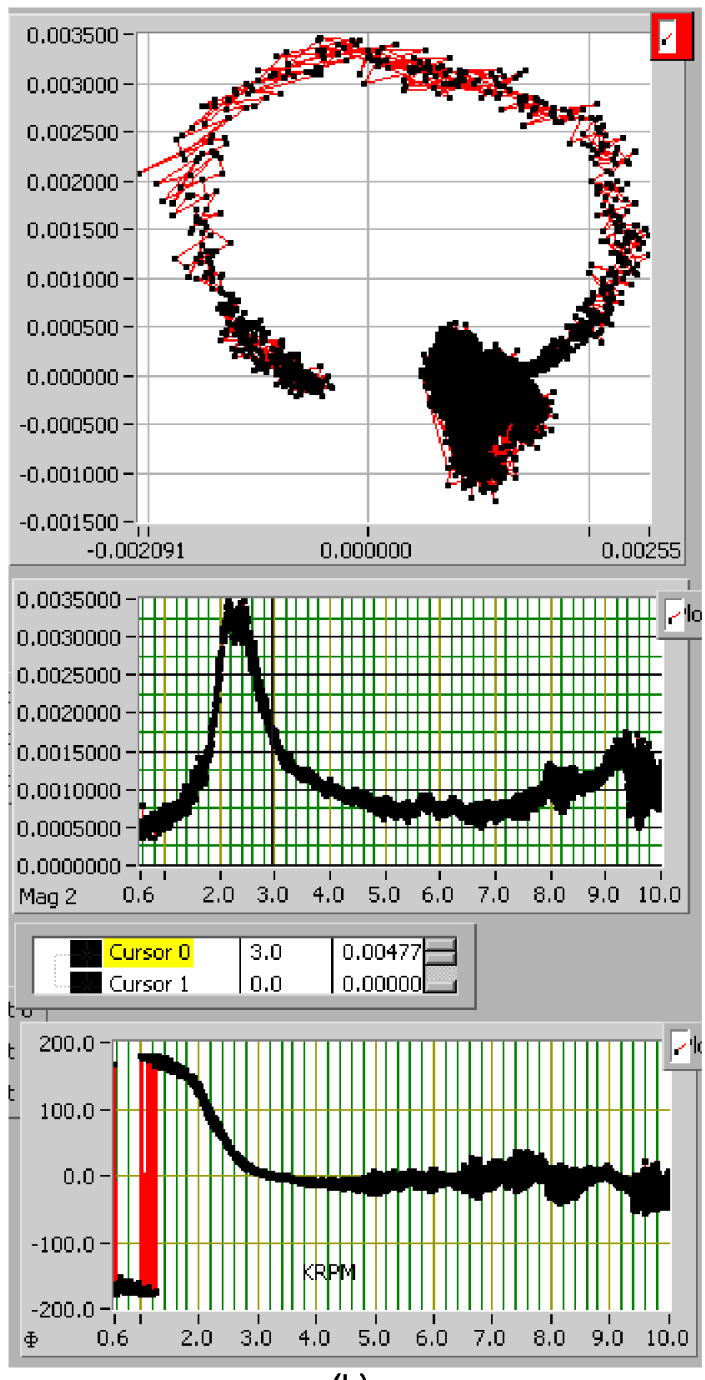

(b)

Figure 11.-10 000-rpm multiple-cycle run comparison. (a) Baseline disk. (b) Notched disk. 


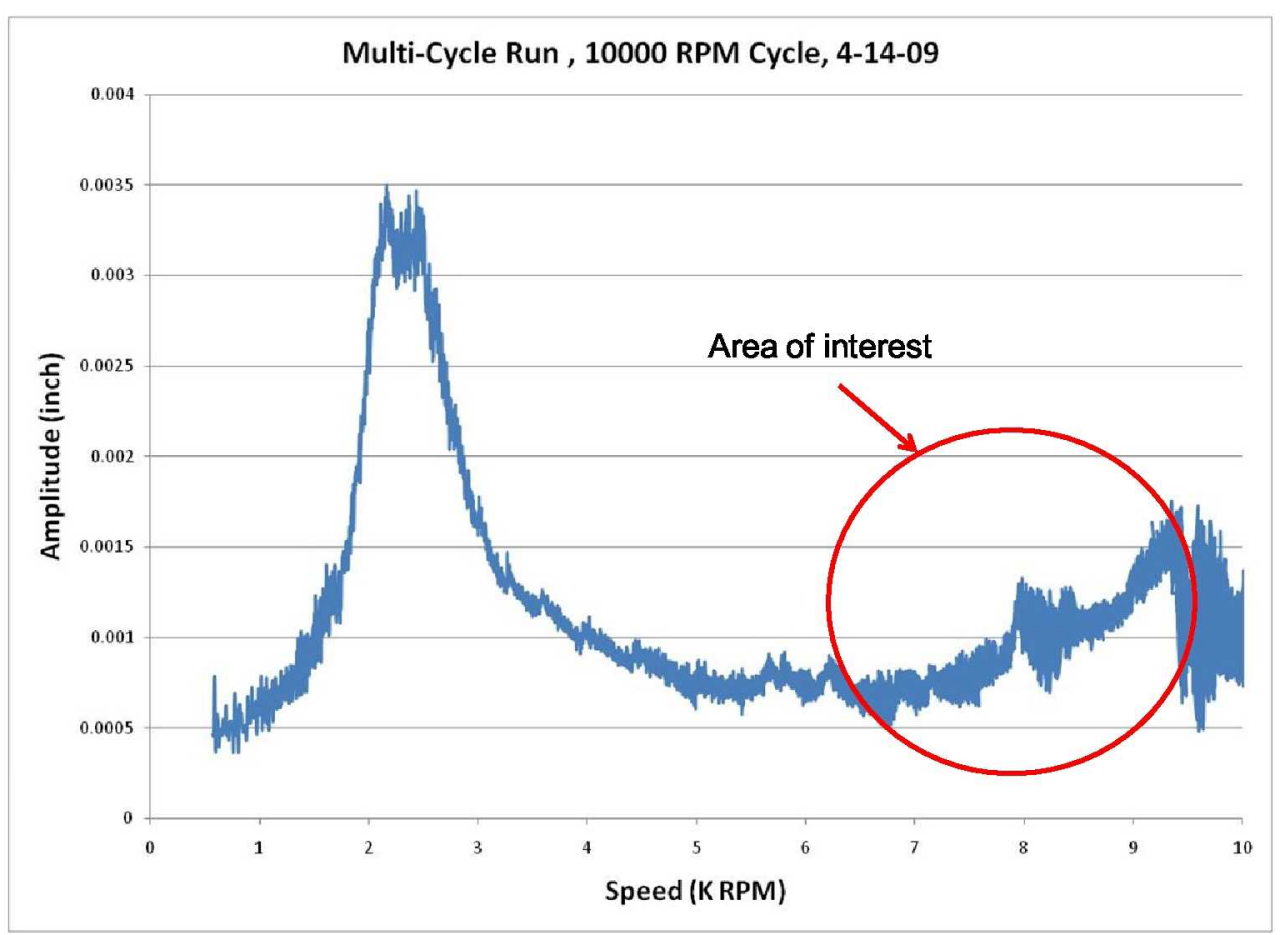

Figure 12.-Vibration amplitude plot for 10000 -rpm multiple-cycle run.

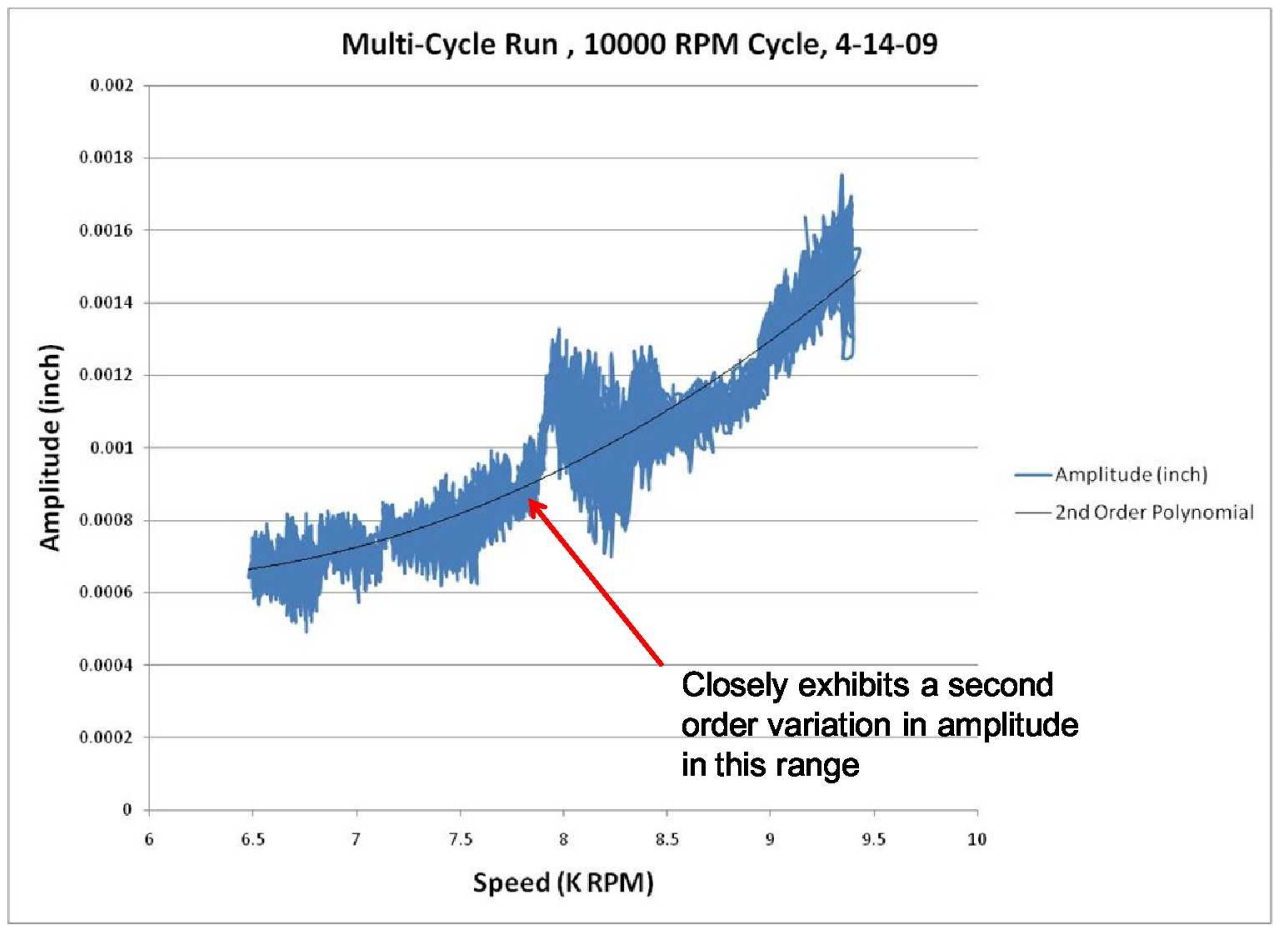

Figure 13.-Detailed vibration amplitude plot for 10000 -rpm multiple-cycle run. 
Although the vibration amplitude data were promising in this region, it was also observed that the second-order speed-dependent variation was not consistent over the entire range and that it appeared to reset itself at a speed of $\sim 9500 \mathrm{rpm}$. Moreover, this amplitude variation was not observed in other test runs, which cast some doubt on whether the effect was entirely due to the notch or to some other factor that is yet to be determined. It was also observed that the vibration vector $x-y$ plot did not exhibit a change in orbit as it did in the 12 000-rpm test case. However, this case yielded the best data so far and showed positive indications of being able to detect a defect such as a crack by analyzing the disk's vibration response, specifically the vibration amplitude as a function of disk speed.

The authors theorized that what made this case different, and more promising than the other test runs, is that this test was conducted toward the end of a day's worth of testing and that many cycles had been placed on the disk prior to this test run. In addition, it was felt that the disk experienced more loading because of the cyclical nature of the test profile. Again, it was postulated that the system was on the verge of being able to make a positive detection using the vibration response crack-detection methodology. Current plans call for improvements to the setup and build-off of this test to further investigate, verify, and develop crack-detection techniques.

\section{Conclusions and Future Work}

NASA Glenn Research Center's High Precision Spin Rig was upgraded successfully, and its operating speed was increased from 5000 to $12000 \mathrm{rpm}$, greatly extending its capability. Along with increasing the speed range, the data system was upgraded to improve the quality of the data and to allow for future expansion of the test rig's instrumentation.

After the upgrade, experiments were conducted on simulated engine disks to demonstrate a potential crack-detection methodology. This crack-detection scheme involved the acquisition of blade-tip-clearance data from both a baseline disk and a defective disk that had a 50.8-mm- (2-in.-) long notch machined onto it. Test runs were conducted over several operational speeds to determine if a simulated crack could be detected by analyzing the disk's vibration response as measured by the blade-tip-clearance sensors. Although the results were promising, they were not entirely conclusive. In the test cases where high operational speeds were encountered, the data exhibited some, but not all of the expected trends. The case that yielded the best results was the 10000 -rpm multiple-cycle test run. This particular case was conducted after many operations had been completed on the disk. It showed a speed-dependent rise in the vibration amplitude, at least for a portion of its speed range, indicating that a crack-induced shift in the disk's center of mass may be detectable. In the other cases, it was noted that the system was on the verge of being able to detect the simulated crack. Further investigations will be conducted with the spin rig to validate this detection concept and others.

The information learned from these experiments will be used to make further improvements to the High Precision Spin Rig and to improve its usefulness in developing and validating flaw-detection concepts. Potential improvements follow:

- Improve the rig setup to eliminate mechanical noise issues

- Implement additional displacement sensors to monitor the motion of the shaft

- Implement the use of microwave-based blade-tip-clearance sensors to improve signal accuracy and reduce noise

- Implement wireless technology for local flaw-detection techniques

- Make improvements to the data and control systems, improving data acquisition and analysis and automating rig motion controls

These improvements are expected to be incorporated as time and testing requirements permit. In conclusion, Glenn's spin rig provides a low-cost venue for developing and validating lower Technology Readiness Level (TRL) detection schemes before employing and trying them out on more expensive and 
complicated components, geometries, and hardware. The test rig showed partial success in demonstrating a crack-detection methodology that involved monitoring and analyzing the vibration response of rotating disks. Additional work is planned to improve the spin rig and to further develop crack- and flaw-detection techniques.

\section{References}

1. Abdul-Aziz, A., Woike, M.R., Lekki, J.D., and Baaklini, G.Y., "Health Monitoring of a Rotating Disk Using a Combined Analytical-Experimental Approach," NASA/TM-2009-215675, 2009.

2. Abdul-Aziz, A., Woike, M.R., Lekki, J.D., and Baaklini, G.Y., "NDE Using Sensor Based Approach to Propulsion Health Monitoring of a Turbine Engine Disk," SPIE's 16th Annual International Symposium on Nondestructive Evaluation for Health Monitoring and Diagnostics, San Diego, CA, Mar. 9-12, 2009.

3. Abdul-Aziz, A., Trudell, J.J., and Baaklini, G.Y., "Finite Element Design Study of a Bladed, Flat Rotating Disk to Simulate Cracking in a Typical Turbine Disk; Part II," SPIE's 11th Annual International Symposium on Nondestructive Evaluation for Health Monitoring and Diagnostics, SPIE, San Diego, CA, Feb. 26-Mar. 2, 2006.

4. Abdul-Aziz, A., Trudell, J.J., and Baaklini, G.Y., "Finite Element Design Study of a Bladed, Flat Rotating Disk to Simulate Cracking in a Typical Turbine Disk," SPIE's 10th International Symposium on Nondestructive Evaluation for Health Monitoring and Diagnostics, San Diego, CA, Mar. 6-10, 2005.

5. Gyekenyesi, A.L., Sawicki, J.T., and Baaklini, G.Y., "Vibration Based Crack Detection in a Rotating Disk, Part 1-An Analytical Study," NASA/TM-2003-212624, 2003.

6. Gyekenyesi, A.L., Sawicki, J.T., Martin, R.E., Haase, W.C., and Baaklini, G.Y., "Vibration Based Crack Detection in a Rotating Disk, Part 2-Experimental Results," NASA/TM-2005-212624/ PART2, 2005.

7. Haase, W.C., and Drumm, M.J., "Detection, Discrimination and Real-Time Tracking of Cracks in Rotating Disks," IEEE 0-7803-7321-X/01, 2002.

8. Structural Alloys Handbook, 1996 ed., edited by J.M. Holt, tech. ed., and C.Y. Ho, ed., CINDAS/Purdue University, West Lafayette, IN, 1996. 


\begin{tabular}{|c|c|c|}
\hline \multicolumn{2}{|c|}{ REPORT DOCUMENTATION PAGE } & $\begin{array}{c}\text { Form Approved } \\
\text { OMB No. 0704-0188 }\end{array}$ \\
\hline \multicolumn{3}{|c|}{ 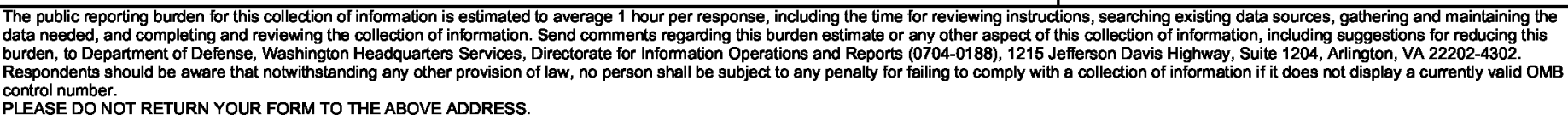 } \\
\hline $\begin{array}{l}\text { 1. REPORT DATE (DD-MM-YYYY) } \\
01-03-2010\end{array}$ & $\begin{array}{l}\text { 2. REPORT TYPE } \\
\text { Technical Memorandum }\end{array}$ & 3. DATES COVERED (From - To) \\
\hline \multirow{3}{*}{\multicolumn{2}{|c|}{$\begin{array}{l}\text { 4. TITLE AND SUBTITLE } \\
\text { Crack-Detection Experiments on Simulated Turbine Engine Disks in NASA Glenn Research } \\
\text { Center's Rotordynamics Laboratory }\end{array}$}} & 5a. CONTRACT NUMBER \\
\hline & & 5b. GRANT NUMBER \\
\hline & & 5c. PROGRAM ELEMENT NUMBER \\
\hline \multirow{3}{*}{\multicolumn{2}{|c|}{$\begin{array}{l}\text { 6. AUTHOR(S) } \\
\text { Woike, Mark, R.; Abdul-Aziz, Ali }\end{array}$}} & 5d. PROJECT NUMBER \\
\hline & & 5e. TASK NUMBER \\
\hline & & $\begin{array}{l}\text { 5f. WORK UNIT NUMBER } \\
\text { WBS 645846.02.07.03.11.03 }\end{array}$ \\
\hline \multicolumn{2}{|c|}{$\begin{array}{l}\text { 7. PERFORMING ORGANIZATION NAME(S) AND ADDRESS(ES) } \\
\text { National Aeronautics and Space Administration } \\
\text { John H. Glenn Research Center at Lewis Field } \\
\text { Cleveland, Ohio 44135-3191 }\end{array}$} & $\begin{array}{l}\text { 8. PERFORMING ORGANIZATION } \\
\text { REPORT NUMBER } \\
\text { E-17226 }\end{array}$ \\
\hline \multirow{2}{*}{\multicolumn{2}{|c|}{$\begin{array}{l}\text { 9. SPONSORING/MONITORING AGENCY NAME(S) AND ADDRESS(ES) } \\
\text { National Aeronautics and Space Administration } \\
\text { Washington, DC 20546-0001 }\end{array}$}} & $\begin{array}{l}\text { 10. SPONSORING/MONITOR'S } \\
\text { ACRONYM(S) } \\
\text { NASA }\end{array}$ \\
\hline & & $\begin{array}{l}\text { 11. SPONSORING/MONITORING } \\
\text { REPORT NUMBER } \\
\text { NASA/TM-2010-216239 }\end{array}$ \\
\hline \multicolumn{3}{|c|}{$\begin{array}{l}\text { 12. DISTRIBUTION/AVAILABILITY STATEMENT } \\
\text { Unclassified-Unlimited } \\
\text { Subject Categories: } 33,35 \text {, and } 07 \\
\text { Available electronically at http://gltrs.grc.nasa.gov } \\
\text { This publication is available from the NASA Center for AeroSpace Information, 443-757-5802 }\end{array}$} \\
\hline
\end{tabular}

\section{SUPPLEMENTARY NOTES}

\section{ABSTRACT}

The development of new health-monitoring techniques requires the use of theoretical and experimental tools to allow new concepts to be demonstrated and validated prior to use on more complicated and expensive engine hardware. In order to meet this need, significant upgrades were made to NASA Glenn Research Center's Rotordynamics Laboratory and a series of tests were conducted on simulated turbine engine disks as a means of demonstrating potential crack-detection techniques. The Rotordynamics Laboratory consists of a highprecision spin rig that can rotate subscale engine disks at speeds up to $12000 \mathrm{rpm}$. The crack-detection experiment involved introducing a notch on a subscale engine disk and measuring its vibration response using externally mounted blade-tip-clearance sensors as the disk was operated at speeds up to $12000 \mathrm{rpm}$. Testing was accomplished on both a clean baseline disk and a disk with an artificial crack: a 50.8-mm(2-in.-) long introduced notch. The disk's vibration responses were compared and evaluated against theoretical models to investigate how successful the technique was in detecting cracks. This paper presents the capabilities of the Rotordynamics Laboratory, the baseline theory and experimental setup for the crack-detection experiments, and the associated results from the latest test campaign.

\section{SUBJECT TERMS}

Gas turbine engines; Integrated Vehicle Health Management (IVHM); Blade tip clearance; Aeropropulsion

\begin{tabular}{|c|c|c|c|c|}
\hline \multicolumn{3}{|c|}{ 16. SECURITY CLASSIFICATION OF: } & \multirow{2}{*}{$\begin{array}{l}\text { 17. LIMITATION OF } \\
\text { ABSTRACT } \\
\text { UU }\end{array}$} & \multirow{2}{*}{$\begin{array}{l}\text { 18. NUMBER } \\
\text { OF } \\
\text { PAGES } \\
21\end{array}$} \\
\hline $\begin{array}{l}\text { a. REPORT } \\
\text { U }\end{array}$ & $\begin{array}{l}\text { b. ABSTRACT } \\
\mathrm{U}\end{array}$ & $\begin{array}{l}\text { c. THIS } \\
\text { PAGE } \\
\text { U }\end{array}$ & & \\
\hline
\end{tabular}

19a. NAME OF RESPONSIBLE PERSON STI Help Desk (email:help@sti.nasa.gov) 19b. TELEPHONE NUMBER (include area code) 443-757-5802 

